\title{
Cyclic AMP-Modulated Phosphorylation of Intermediate Filament Proteins in Cultured Avian Myogenic Cells
}

\author{
DAVID L. GARD AND ELIAS LAZARIDES* \\ Division of Biology, California Institute of Technology, Pasadena, California 91125
}

Received 7 April 1982/Accepted 9 June 1982

\begin{abstract}
The intermediate filament proteins desmin and vimentin and the muscle tropomyosins were the major protein phosphate acceptors in 8-day-old myotubes incubated for $4 \mathrm{~h}$ in medium containing radiolabeled phosphate. The addition of isoproterenol or 8-bromo-cyclic AMP (BrcAMP) resulted in a two- to threefold increase in incorporation of ${ }^{32} \mathrm{PO}_{4}$ into both desmin and vimentin, whereas no changes in the incorporation of ${ }^{32} \mathrm{PO}_{4}$ into tropomyosin or other cellular proteins were observed. The BrcAMP- or hormonally induced increase in ${ }^{32} \mathrm{PO}_{4}$ incorporation into desmin and vimentin was independent of protein synthesis and was not caused by stimulation of protein phosphate turnover. In addition, BrcAMP did not induce significant changes in the specific activity of the cellular ATP pool. These data suggest that the observed increase in ${ }^{32} \mathrm{PO}_{4}$ incorporation represented an actual increase in phosphorylation of the intermediate filament proteins desmin and vimentin. Two-dimensional tryptic analysis of desmin from 8-day-old myotubes revealed five phosphopeptides of which two showed a 7- to 10-fold increase in ${ }^{32} \mathrm{PO}_{4}$ incorporation in BrcAMP-treated myotubes. Four of the phosphopeptides identified in desmin labeled in vivo were also observed in desmin phosphorylated in vitro by bovine heart cAMP-dependent protein kinase. Although phosphorylation of desmin and vimentin was apparent in myogenic cells at all stages of differentiation, BrcAMP- and isoproterenol-induced increases in phosphorylation of these proteins were restricted to mature myotubes. These data strongly suggest that in vivo phosphorylation of the intermediate filament proteins desmin and vimentin is catalyzed by the cAMP-dependent protein kinases and that such phosphorylation may be regulated during muscle differentiation.
\end{abstract}

Cytoplasmic filaments with diameters of 9 to $12 \mathrm{~nm}$ have been described in a wide variety of cell types from diverse sources. Known collectively as intermediate filaments (IFs), they comprise a heterogeneous class of filaments which, although similar in morphology, are composed of one or more biochemically distinct subunit proteins. It is now recognized that a cell may possess one or more subclasses of IFs whose expression is determined by the tissue of origin and state of differentiation (for a review, see reference 14). Avian embryonic myotubes cultured in vitro possess two IF proteins $(1,6,7,9)$ : desmin, the IF protein first isolated from smooth muscle $(12,23)$; and vimentin, which is commonly found in fibroblastic cells (7). In immature skeletal myotubes these two IF proteins coexist in an extensive network of cytoplasmic filaments $(1,9)$. Late in myogenesis, however, both of these IF proteins become associated with the $\mathrm{Z}$ lines of myofibril bundles (9), where they form a collar-like lattice surrounding and interlinking $Z$ discs of adjacent myofibrils (10, 11). The molecular regulatory mechanisms un- derlying this redistribution of IFs during myogenesis remain obscure. One common biochemical characteristic of all IFs is phosphorylation of their subunit proteins (14). Protein phosphorylation and dephosphorylation are known to be important regulatory events in many cellular metabolic processes (13), and it is possible that similar mechanisms may be involved in the regulation of cellular architecture (22).

A growing body of evidence suggests that phosphorylation of IF proteins may be modulated by cyclic AMP (cAMP). Phosphorylation of vimentin in S49 cells is enhanced by treatment with $\beta$-adrenergic agonists or cAMP analogs and is deficient in mutant cells lacking functional cAMP-dependent protein kinase (25). Similarly, C6 glioma-neuroblastoma hybrids show increased phosphorylation of vimentin when treated with norepinephrine (2). We have previously found that both desmin and vimentin, the IF proteins found in avian skeletal myotubes, are phosphorylated by cAMP-dependent protein kinase in vitro (20). In this paper we present evidence that phosphorylation of desmin and 
vimentin in chicken embryonic skeletal myotubes is stimulated by $\beta$-adrenergic hormones or by 8-bromo-cAMP (BrcAMP), resulting in increased phosphorylation of specific desmin tryptic peptides. In addition, we report that the response of cultured myogenic cells to hormones or BrcAMP depends upon the state of differentiation of these cells.

\section{MATERIALS AND METHODS}

Carrier-free ${ }^{32} \mathrm{PO}_{4}$ (orthophosphate in $0.1 \mathrm{~N} \mathrm{HCl}$ ) and Aquasol II scintillation fluid were obtained from New England Nuclear Corp. Norepinephrine (DLarterenol) was obtained from Calbiochem. Trypsintolylsulfonyl phenylalanyl chloromethyl ketone (TPCK) was from Worthington Diagnostics. Cellulose plates for thin-layer chromatography were obtained from Eastman Chemical Products, Inc. (no. 13255). \pm Isoproterenol, theophylline, BrcAMP, 8-bromo-guanosine 3',5'-phosphate (BrcGMP), 8-bromo-adenosine $5 '$-monophosphate (BrAMP), and catalytic subunit from bovine heart cAMP-dependent protein kinase were obtained from Sigma Chemical Co. Sources for the electrophoresis reagents have been described previously (12).

Cell cultures. Cultures of embryonic myogenic cells were prepared from 10-day-old chicken embryos as previously described (9). Cultures used for experiments within $24 \mathrm{~h}$ of plating were seeded at $5 \times 10^{3}$ to 7 $\times 10^{5}$ cells per $60-\mathrm{mm}$ collagen-coated petri plate. Other myogenic cultures were seeded at $2 \times 10^{5}$ to $3 \times$ $10^{5}$ cells per $60-\mathrm{mm}$ collagen-coated plate, except as noted. Myotube cultures were treated with 10 or 20 $\mu \mathrm{M}$ cytosine arabinofuranoside on days 4 to 7 to prevent overgrowth by residual fibroblastic cells. Greater than $75 \%$ of the cell nuclei were present in multinucleate myotubes in cultures used for these experiments.

${ }_{32} \mathrm{PO}_{4}$ incubations. Duplicate cultures in $60-\mathrm{mm}$ petri plates were washed twice with $3 \mathrm{ml}$ of phosphate-free minimal essential medium and incubated for $4 \mathrm{~h}$ in phosphate-free minimal medium supplemented with $1 \%$ horse serum containing ${ }^{32} \mathrm{PO}_{4}(50 \mu \mathrm{Ci} / \mathrm{ml})$. Hormones or CAMP analogs were added to the final concentrations indicated for $\mathbf{4 5}$ min (or indicated time) before the end of the $4 \mathrm{~h}^{32} \mathrm{PO}_{4}$ incubation. Labeled cultures were washed once with cold phosphate-buffered saline ( $0.14 \mathrm{M} \mathrm{NaCl}, 3 \mathrm{mM} \mathrm{KCl}, 10 \mathrm{mM}$ sodiumpotassium phosphate [pH 7.2]), scraped from petri dishes with a rubber policeman, and pelleted at top speed in a tabletop centrifuge (International Equipment Co.) (approximately $1,000 \times g$ ). Cell pellets were then solubilized for 3 to $5 \mathrm{~min}$ at $100^{\circ} \mathrm{C}$ in $75 \mu$ l of sample buffer containing $0.2 \%$ sodium dodecyl sulfate (SDS), $50 \mathrm{mM}$ Tris-hydrochloride (pH 6.8), 1\% 2mercaptoethanol, and $15 \%$ glycerol. Samples were then prepared immediately for electrophoresis (see below) or frozen at $-20^{\circ} \mathrm{C}$ for later use.

Two-dimensional electrophoresis. In using the $\mathrm{O}^{\prime} \mathrm{Far}$ rell two-dimensional isoelectric-focusing SDS-polyacrylamide gel electrophoresis (IEF/SDS-PAGE) technique (21), we found that vimentin is particularly sensitive to degradation by endogenous proteases when present in urea extracts. This proteolysis was resistant to most of the common protease inhibitors or divalent cation chelating agents but could be prevent- ed by solubilization in buffers containing $0.2 \%$ SDS for 2 to $5 \mathrm{~min}$ at $100^{\circ} \mathrm{C}$. Hydrolysis of protein phosphate by phosphatase activity is also minimized by this procedure. These SDS-treated whole cell extracts were then cooled on ice and mixed with equal volumes of saturated urea solution. Duplicate 10- $\mu$ l portions were taken to determine trichloroacetic acid (TCA)precipitable radioactivity (see below).

Each sample $\left(1 \times 10^{5}\right.$ to $2 \times 10^{5} \mathrm{cpm}$; approximately 100 to $150 \mu \mathrm{l}$ ) was electrophoresed on 10-cm O'Farrell isoelectric-focusing gels modified by the omission of nonionic detergent. The second (SDS-PAGE) dimension was performed as previously described (12). Gels were stained, destained overnight, dried, and autoradiographed for the indicated times on Kodak XR-A film and Du Pont Cronex Lightning Plus intensifying screens. Although the overall isoelectric focusing of proteins from SDS-treated myotubes was comparable to that seen in O'Farrell gels (Fig. 1), some differences were noted. Most obvious was the appearance of a prominent 52,000 -dalton protein (slightly more basic than vimentin) which was not seen in urea-Nonidet $P$ 40 extracts of myotubes (inset, Fig. 1C). Whether this species represents an artifactual modification of vimentin has not yet been determined. Additionally, the tubulins were much less conspicuous in SDS-treated extracts. However, the proteolytic degradation was substantially reduced in the SDS-treated extract, allowing a more accurate assessment of changes in the phosphorylation of this protein.

For quantitation of ${ }^{32} \mathrm{PO}_{4}$ incorporation into specific proteins, individual gel slices were cut out and counted in Aquasol with an efficiency of approximately $95 \%$.

Determination of TCA-precipitable ${ }^{32} \mathrm{PO}_{4}$ incorporation. Duplicate samples $(10 \mu \mathrm{l})$ were spotted on Whatman 3 MM filter disks. Filters were washed for $20 \mathrm{~min}$ in $10 \% \mathrm{TCA}$ at $90^{\circ} \mathrm{C}$ and then at room temperature for $15 \mathrm{~min}$ in each of the following: 10\% TCA, two washes of $5 \%$ TCA, two washes of $95 \%$ ethyl alcohol, and two washes of ethyl ether. Filters were dried and counted in Aquasol II.

Two-dimensional tryptic mapping. Two-dimensional tryptic mapping of ${ }^{32} \mathrm{PO}_{4}$-labeled desmin and vimentin was performed essentially as described previously (19). Myotubes ( 8 days old; $10^{6}$ cells per $100-\mathrm{mm}$ plate) were labeled as described above for $4 \mathrm{~h}$ with $100 \mu \mathrm{Ci}$ of ${ }^{32} \mathrm{PO}_{4}$ per $\mathrm{ml}$. BrcAMP or BrAMP was added during the last hour of the labeling period. IEF/SDS-polyacrylamide gels were stained and then destained overnight, and the appropriate proteins were excised. Gel slices were washed for 12 to $24 \mathrm{~h}$ in three $500-\mathrm{ml}$ changes of $10 \%$ ethanol and for $2 \mathrm{~h}$ in $95 \%$ ethanol and then vacuum dried. Dried gel slices were rehydrated in $200 \mathrm{mM}$ ammonium bicarbonate containing $0.2 \mathrm{mg}$ of trypsin-TPCK per ml. Approximately $10 \mu \mathrm{l}$ of trypsin in bicarbonate buffer was added per $1-\mathrm{mm}^{3}$ dried gel slice. Digestion was carried out for 8 to $12 \mathrm{~h}$ at $37^{\circ} \mathrm{C}$, and then an aliquot of trypsin in $1 \mathrm{ml}$ of bicarbonate buffer was added. Digestion and peptide elution were continued at $37^{\circ} \mathrm{C}$ for 18 to $24 \mathrm{~h}$, followed by lyophilization of the supernatant. Samples (approximately equal amounts of protein representing 500 to 2,000 cpm) were spotted onto cellulose thin-layer plates and electrophoresed at $800 \mathrm{~V}$ for $\mathbf{4 5} \mathrm{min}$ in acetic acid:formic acid:water (11.4:10:379), pH 1.9. After being dried for $\mathbf{2 ~} \mathrm{h}$, the plates were chromatographed in butanol: acetic acid:pyridine:water $(60: 12: 40: 48)$ for the second 
dimension. The locations of phosphopeptides were determined by authoradiography. Quantitation of phosphopeptides was accomplished by scintillation counting in Aquasol II, with an efficiency of approximately $95 \%$.

Preparation of desmin labeled in vitro by bovine heart cAMP-dependent protein kinase was done as described by O'Connor et al. (20).

\section{RESULTS}

Phosphorylation of desmin and vimentin in 8day-old myotubes. We have previously shown that the IF proteins desmin and vimentin are phosphorylated in avian embryonic myotubes cultured in vitro, and that both phosphorylated and nonphosphorylated species of these proteins are components of the Triton- $\mathrm{KCl}$-insoluble myotube cytoskeleton (18). For this report we examined the ${ }^{32} \mathrm{P}$-labeled phosphoproteins from 8-day-old myotubes by two-dimensional IEF/ SDS-PAGE (Fig. 1). The protein species most prominently labeled in myotubes of this age are the muscle tropomyosins and two proteins we previously identified as the IF proteins desmin and vimentin, based upon their electrophoretic mobility, isoelectric point, and their enrichment in Triton-KCl-treated cytoskeletons of myotubes (8). Several other less heavily labeled phosphoproteins were also observed, as well as a large amount of radioactive phosphate-containing material which did not focus in the IEF gel, remaining near the basic end (top) of the gel.
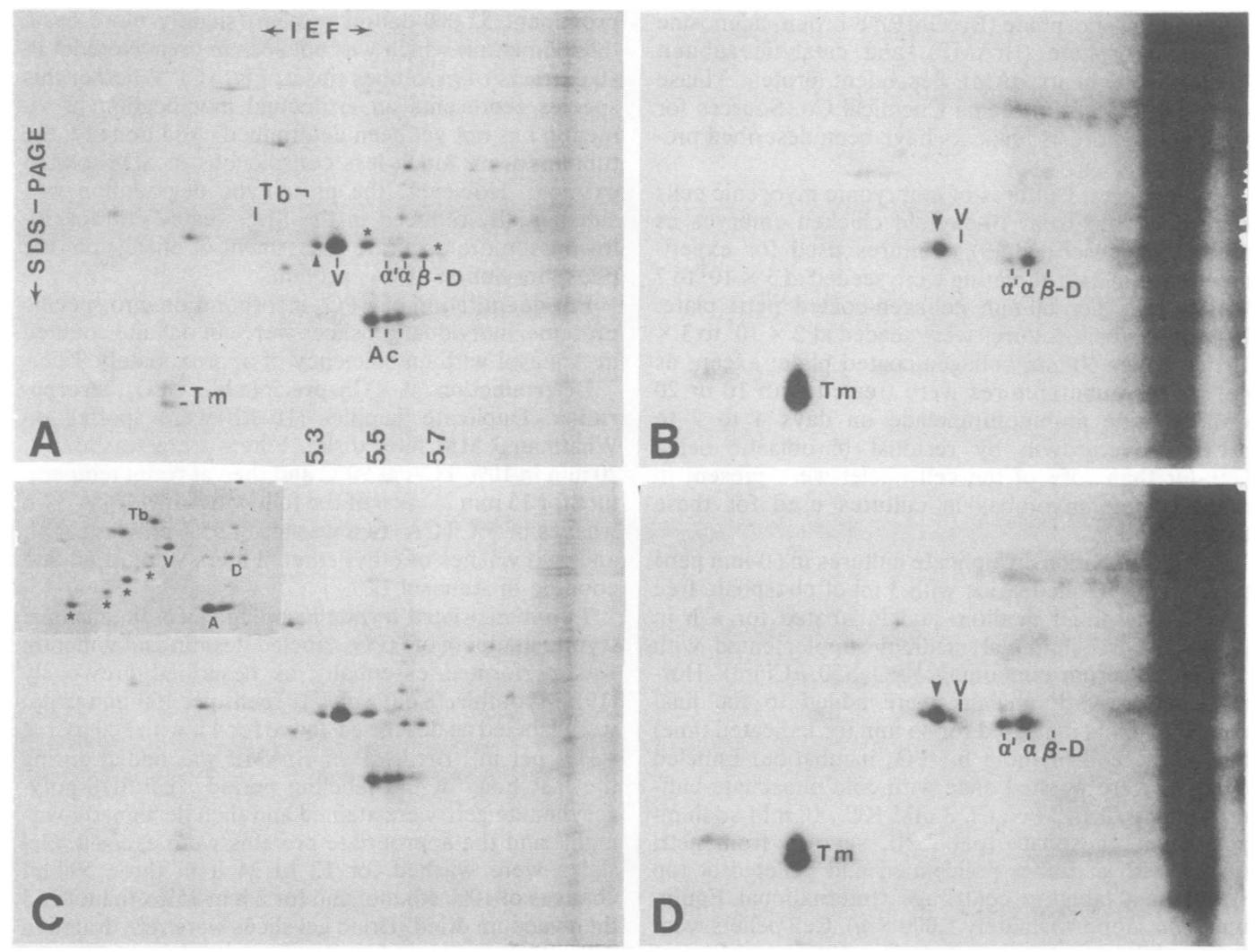

FIG. 1. Two-dimensional IEF/SDS-PAGE analysis of phosphorylation of IF proteins in control and isoproterenol-treated 8-day-old myotubes. (A and B) Stained gel and corresponding autoradiogram (12-h exposure) from myotubes labeled with ${ }^{32} \mathrm{PO}_{4}$. Isoelectric focusing is from right to left (basic to acid) in all of the gels presented. The approximate pH range is shown in A. SDS-PAGE is from top to bottom. The positions of the three desmin species ( $\alpha^{\prime}, \alpha$ - and $\left.\beta-D\right)$, vimentins (V, arrow), tropomyosins (Tm), actins (Ac), and tubulins (Tb) are shown. The asterisks denote an unidentified protein seen in SDS-treated but not in Nonidet P-40-treated extracts of myotubes (see the text). The autoradiogram (B) reveals that tropomyosins, $\alpha$-desmin, and an acidic vimentin species (arrow) are the major phosphate acceptors. (C and D) No differences are apparent in the protein composition observed in myotubes treated with $1 \mu \mathrm{M}$ isoproterenol, as shown by Coomassie-stained gel (C). The corresponding autoradiogram reveals increased incorporation of ${ }^{32} \mathrm{PO}_{4}$ into vimentin and desmins $\left(\alpha-\right.$ and $\alpha^{\prime}$ desmin), but not into other cellular phosphoproteins (such as tropomyosin). The inset in $\mathrm{C}$ shows a portion of an IEF/SDS-PAGE gel of a myotube urea extract exhibiting substantial proteolysis of vimentin (stars). 
This material may represent ${ }^{32} \mathrm{P}$-labeled, poorly solubilized protein.

Direct comparison of the autoradiogram with the stained gel (Fig. 1A and B) revealed that (as previously reported; 18 ) $\alpha$-desmin was the most heavily labeled desmin species, with a lesser amount of ${ }^{32} \mathrm{PO}_{4}$ incorporation into the more acidic $\alpha^{\prime}$-desmin, and no label in $\beta$-desmin. Similarly, ${ }^{32} \mathrm{PO}_{4}$ incorporation was greatest into a single acidic variant of vimentin, with slight incorporation into a second, poorly resolved, more acidic variant, and no label in the major, most basic vimentin species. These results suggested that the acidic variants of desmin and vimentin are derived by post-translational phosphorylation of the respective more basic protein species $(17,20$; see below).

B-Adrenergic agonists increase incorporation of ${ }^{32} \mathrm{PO}_{4}$ into IF proteins. Addition of $1 \mu \mathrm{M}$ isoproterenol during the last $45 \mathrm{~min}$ of the 4-h ${ }^{32} \mathrm{PO}_{4}$ incubation period resulted in specific increases in the incorporation of ${ }^{32} \mathrm{PO}_{4}$ into the IF proteins desmin and vimentin (Fig. 1C and D). However, isoproterenol did not induce signifcant changes in the protein composition of treated myotubes as determined by Coomassie blue staining (compare Fig. $1 \mathrm{~A}$ and $\mathrm{C}$ ). No changes in the incorporation of ${ }^{32} \mathrm{PO}_{4}$ into other cellular proteins, notably the muscle tropomyosins, were apparent under these conditions. Quantitation of excised ${ }^{32} \mathrm{P}$-labeled protein spots from eight experiments revealed that tropomyosin contained $0.2 \pm 0.1 \%$ of the total TCA-precipitable ${ }^{32} \mathrm{PO}_{4}$ in the control myotubes and $0.2 \pm$ $0.1 \%$ of the total TCA-precipitable ${ }^{32} \mathrm{PO}_{4}$ in the isoproterenol-treated cells. We thus used ${ }^{32} \mathrm{PO}_{4}$ incorporation into tropomyosin as an internal standard to normalize differences in gel loading between each experiment. These results and the equation used for their calculation are shown in Table 1. Incorporation of ${ }^{32} \mathrm{PO}_{4}$ into desmin and vimentin was found to be stimulated approximately twofold in 8-day-old myotubes treated with $1 \mu \mathrm{M}$ isoproterenol. This response was dose dependent, reaching maximum stimulation at $1 \mu M$ (data not shown). Similar increases were also observed with the weak $\beta$-agonist norepinephrine (data not shown).

BrcAMP stimulated phosphorylation of IF proteins. $\beta$-Adrenergic hormones such as isoproterenol elicit cellular responses through increases in the intracellular levels of cAMP. We therefore investigated the effects of the cAMP derivative BrcAMP and the phosphodiesterase inhibitor theophylline on phosphorylation of desmin and vimentin in 8-day-old myotubes. Cotreatment of these myotubes with BrcAMP and theophylline resulted in a threefold increase in the incorporation of ${ }^{32} \mathrm{PO}_{4}$ into desmin and vimentin (Fig. 2, Table 1) with no apparent increase in labeling for tropomyosin. This increase was similar to but slightly greater in magnitude than that observed in isoproterenol-treated myotubes. The appearance of a third phosphorylated desmin variant, more acidic than $\alpha^{\prime}$-desmin, can be seen in myotubes treated with BrcAMP (Fig. 2B). Theophylline alone had no significant effect on IF protein phosphorylation (Table 1), and the simultaneous inclusion of theophylline and BrcAMP did not enhance the effect observed with BrcAMP alone (data not shown), consistent with the reported resistance of BrcAMP to cellular phosphodiesterases $(15,16)$. Most of the experiments on the effect of cyclic nucleotides were conducted in the presence of theophylline, except where noted. The noncyclic analog BrAMP had no significant effect on ${ }^{32} \mathrm{PO}_{4}$ incor-

TABLE 1. Response of 7- to 8-day-old myotubes to isoproterenol and BrcAMP

\begin{tabular}{|c|c|c|c|}
\hline \multirow{2}{*}{$\begin{array}{l}\text { Addition to labeled } \\
\text { myotubes (amt) }\end{array}$} & \multicolumn{2}{|c|}{$\begin{array}{l}\text { Increase in IF protein } \\
\text { phosphorylation }^{b}\end{array}$} & \multirow{2}{*}{$\begin{array}{l}\text { No. of } \\
\text { expts }\end{array}$} \\
\hline & $\begin{array}{l}\text { Total } \\
\text { desmin }\end{array}$ & Vimentin & \\
\hline $\begin{array}{l}\text { Isoproterenol (1 } \\
\boldsymbol{\mu M})\end{array}$ & $2.0 \pm 0.2$ & $1.8 \pm 0.2$ & 3 \\
\hline $\begin{array}{l}\text { BrcAMP }(0.5 \\
\text { mM) plus } \\
\text { theophylline } \\
(0.5 \mathrm{mM})\end{array}$ & $2.8 \pm 0.2$ & $2.9 \pm 0.2$ & 3 \\
\hline $\begin{array}{l}\text { BrcGMP (1 mM) } \\
\text { plus } \\
\text { theophylline } \\
(1 \mathrm{mM})\end{array}$ & $1.4 \pm 0.1$ & & 2 \\
\hline $\begin{array}{l}\text { Theophylline (1 } \\
\text { mM) }\end{array}$ & $1.2 \pm 0.2$ & $1.3 \pm 0.2$ & 2 \\
\hline BrAMP (1 mM) & 1.1 & 1.1 & 1 \\
\hline $\begin{array}{l}\text { BrcAMP }(0.5 \\
\text { mM), } \\
\text { theophylline } \\
(1 \mu \mathrm{M}), \text { plus } \\
\text { isoproterenol } \\
(1 \mu \mathrm{M})\end{array}$ & 3.1 & 1.9 & 1 \\
\hline $\begin{array}{l}\text { BrcAMP }(0.5 \\
\text { mM) plus } \\
\text { theophylline } \\
(0.5 \mathrm{mM})^{c}\end{array}$ & $2.9 \pm 0.3$ & $2.4 \pm 0.5$ & 2 \\
\hline $\begin{array}{c}\text { Isoproterenol (1 } \\
\mu \mathrm{M})^{c}\end{array}$ & 1.9 & 2.2 & 1 \\
\hline \multicolumn{4}{|c|}{$\begin{array}{l}\text { additions were made during last } 45 \mathrm{~min} \text { of a } 4 \mathrm{~h} \\
\text { labeling period. } \\
b \text { The increase was calculated with tropomyosin } \\
\text { used as an internal standard to normalize gel loading } \\
\text { by the following formula: increase = [(label in des- } \\
\text { min)/(label in tropomyosin) in experiments] } \div \text { [(label } \\
\text { in desmin)/(label in tropomyosin) in controls], } \pm \text { stan- } \\
\text { dard deviation where applicable. } \\
\text { c Cells were pretreated with cycloheximide (100 } \mu \mathrm{g} / \\
\text { ml) } 1 \mathrm{~h} \text { before hormone or BrcAMP was added; this } \\
\text { amount was sufficient to inhibit greater than } 95 \% \text { of } \\
\text { protein synthesis within } 30 \text { min. }\end{array}$} \\
\hline
\end{tabular}




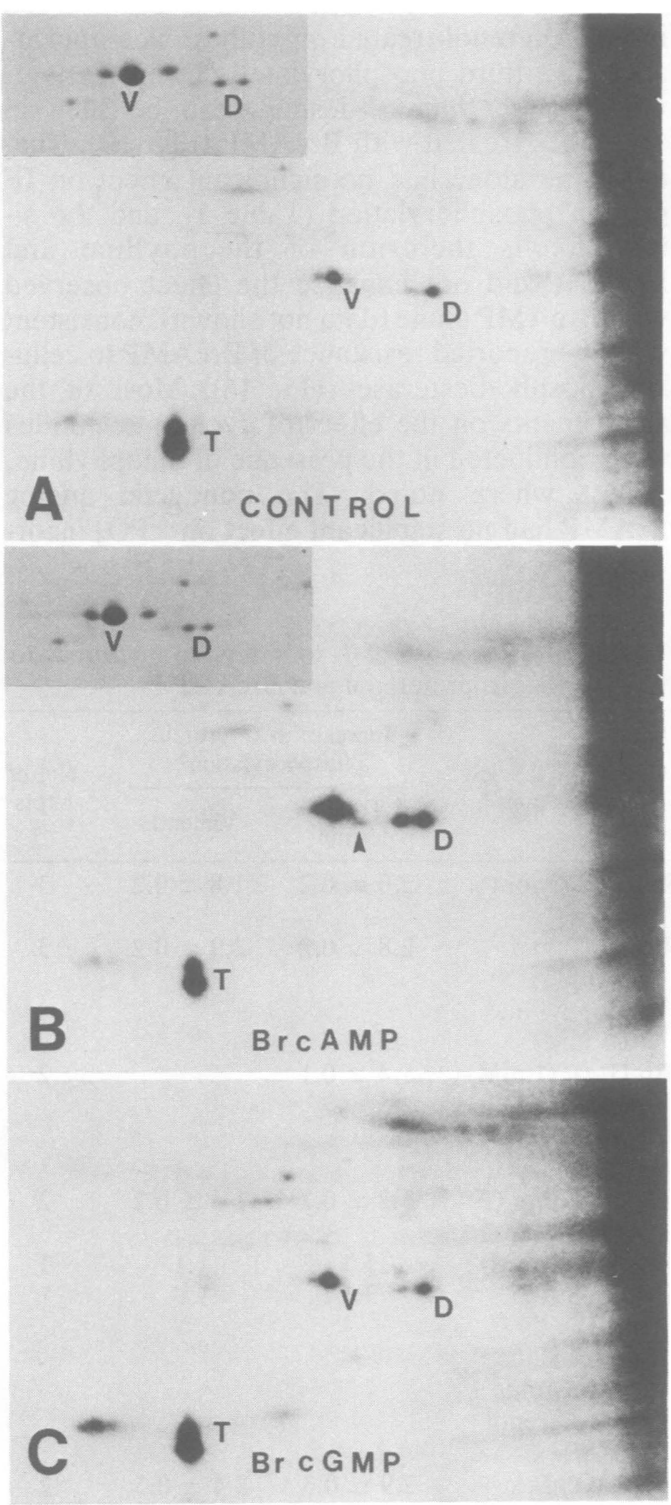

FIG. 2. BrcAMP stimulates phosphorylation of desmin and vimentin in 7-day-old myotubes. Myotubes were labeled for $4 \mathrm{~h}$ with ${ }^{32} \mathrm{PO}_{4}(\mathrm{~A})$ and treated for $45 \mathrm{~min}$ with either $1 \mathrm{mM}$ BrcAMP plus $1 \mathrm{mM}$ theophylline (B) or $1 \mathrm{mM}$ BrcGMP plus $1 \mathrm{mM}$ theophylline (C). BrcAMP plus theophylline resulted in a substantial increase in ${ }^{32} \mathrm{PO}_{4}$ incorporation into des$\min (D)$ and vimentin (V). Note the appearance of ${ }^{32} \mathrm{PO}_{4}$ in a third acidic desmin species (arrow). Staining with Coomassie blue (insets) revealed no changes in the ratio of the desmin isoelectric variants in control or BrcAMP plus theophylline-treated cells. BrcGMP and theophylline (C) had only a slight effect on ${ }^{32} \mathrm{PO}_{4}$ incorporation into desmin and vimentin. Autoradiograms were exposed for $18 \mathrm{~h}$. poration into IF proteins (Table 1), indicating that the increase observed with BrcAMP is specific for the cyclic nucleotide.

To ascertain whether the BrcAMP-induced increase in ${ }^{32} \mathrm{PO}_{4}$ incorporation into desmin and vimentin represented an actual increase in phosphorylation of these proteins, we performed several additional experiments. The possibility of cAMP-induced increases in protein phosphate turnover was ruled out by incubating 8-day-old myotubes for 2,20 , or $48 \mathrm{~h}$ in $0.5 \mathrm{mM}$ BrcAMP and then for $2 \mathrm{~h}$ with ${ }^{32} \mathrm{PO}_{4}$ in the presence of BrcAMP. No increase in ${ }^{32} \mathrm{PO}_{4}$ incorporation in IF proteins was observed compared with parallel untreated cultures (data not shown).

We have previously reported that phosphorylation of desmin and vimentin is independent of protein synthesis (18). We found that the isoproterenol- and BrcAMP-induced increases in ${ }^{32} \mathrm{PO}_{4}$ incorporation into these proteins were also independent of protein synthesis. The addition of cycloheximide $1 \mathrm{~h}$ before the addition of either isoproterenol or BrcAMP had little effect on the subsequent stimulation of ${ }^{32} \mathrm{PO}_{4}$ incorporation by these agents (Table 1 ).

Finally, the specific increase in incorporation of ${ }^{32} \mathrm{PO}_{4}$ into the IF proteins (without significant increases in other cellular phosphoproteins such as tropomyosin) made it unlikely that cAMP induced a change in the specific activity of the cellular ATP pool, yielding an apparent increase in phosphorylation. To confirm this, we determined the specific activity of the cellular ATP pools from control and BrcAMP-treated myotubes by the luciferase ATP assay described by Dolecki et al. (4). No differences in the specific activity of ATP pools were detected in the BrcAMP-treated myotubes in three independent experiments (data not shown). From these results we conclude that the increase in ${ }^{32} \mathrm{PO}_{4}$ incorporation into desmin and vimentin induced by isoproterenol or BrcAMP represents an actual increase in phosphorylation of these two proteins.

When isoproterenol and BrcAMP were administered together at concentrations which yielded maximal responses when added separately $(1 \mu \mathrm{M}$ isoproterenol, $0.5 \mathrm{mM}$ BrcAMP plus theophylline), no additive effect was detected, yielding a response equivalent to that observed with BrcAMP plus theophylline alone (Table 1). This suggests that $\beta$-adrenergic agonists and BrcAMP act through similar molecular mechanisms, presumably via an increase in the effective intracellular cAMP level and subsequent activation of the CAMP-dependent protein kinase.

Eight-day-old myotubes treated with BrcGMP and theophylline showed only slight increases in IF protein phosphorylation (Fig. 2C, Table 1) 
which were less than $25 \%$ of the response observed in parallel cultures treated with the identical concentration of BrcAMP.

Tryptic analysis of desmin phosphopeptides. We have previously used two-dimensional tryptic peptide mapping to compare the phosphopeptides from desmin phosphorylated in vivo or in vitro by bovine heart cAMP-dependent protein kinase $(19,20)$. A sizable fraction of ${ }^{32} \mathrm{PO}_{4}$ in these earlier preparations migrated as inorganic phosphate, suggesting that some hydrolysis of phosphopeptides had occurred during sample preparation. The use of modified conditions for the preparation and digestion of samples for peptide mapping resulted in substantially less phosphate hydrolysis. Representative peptide maps of ${ }^{32} \mathrm{PO}_{4}$-labeled desmin phosphorylated in vivo from 8-day-old myotubes are shown in Fig. 3. Cultures were incubated with ${ }^{32} \mathrm{PO}_{4}$ for $4 \mathrm{~h}$, and BrcAMP-treated cells received $1 \mathrm{mM}$ BrcAMP during the last hour of the ${ }^{32} \mathrm{PO}_{4}$ incubation.

The total desmin obtained from ${ }^{32} \mathrm{PO}_{4}$-labeled control myotubes exhibited two or three major ${ }^{32}$ P-labeled peptides and several minor species. The major peptide designated $\mathrm{A}$ and the peptide designated B (Fig. 3A) correspond to those peptides previously identified in ${ }^{32} \mathrm{P}$-labeled desmin phosphorylated in vivo or in vitro (20). The ${ }^{32} \mathrm{P}$-labeled peptides of desmin from 8-day-old

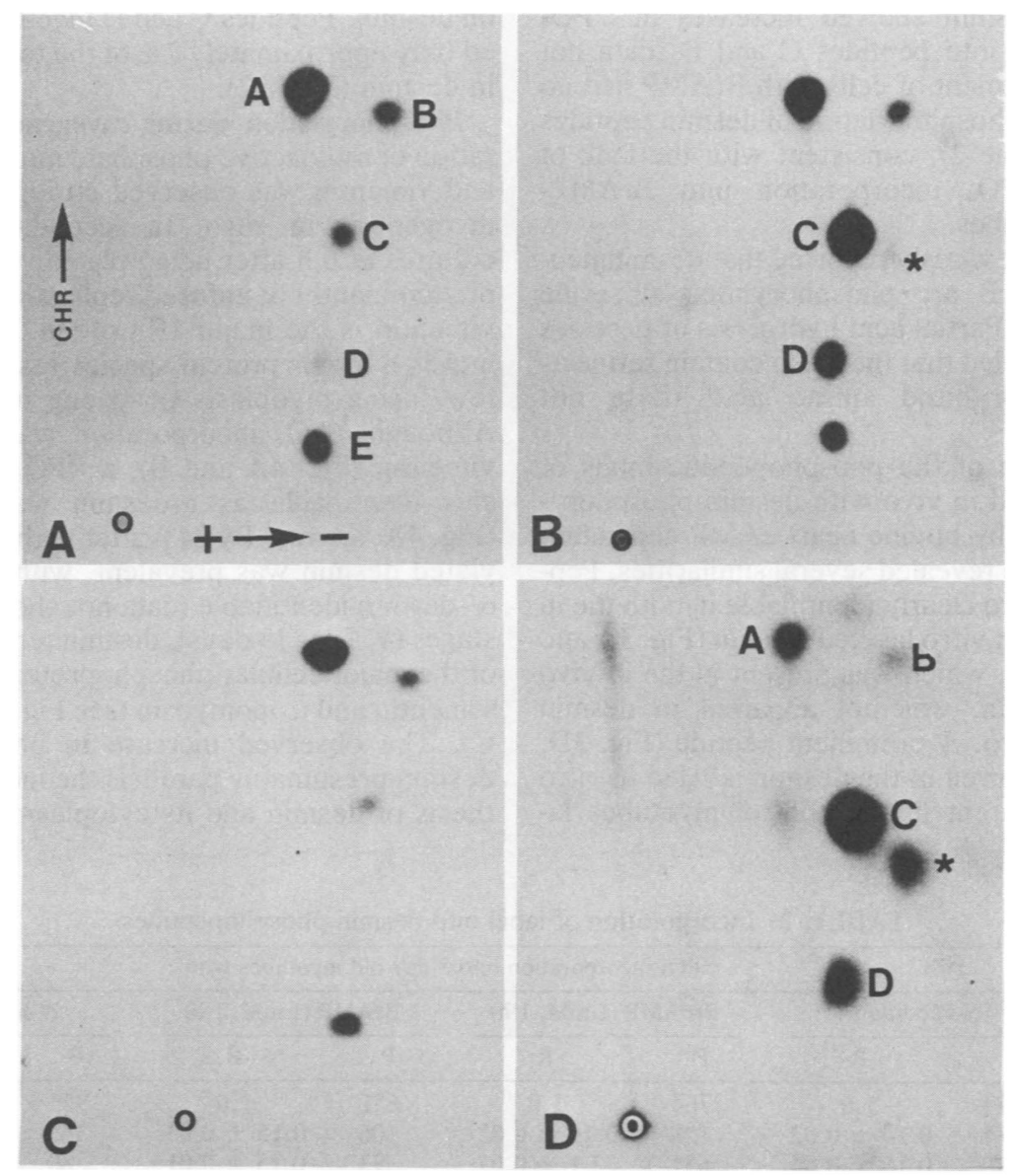

FIG. 3. Tryptic peptide analysis of phosphorylated desmin from 8-day-old myotubes. Myotubes were labeled for $4 \mathrm{~h}$ with ${ }^{32} \mathrm{PO}_{4}(100 \mu \mathrm{Ci} / \mathrm{ml})$ and treated for $1 \mathrm{~h}$ with either $1 \mathrm{mM}$ BrcAMP or $1 \mathrm{mM}$ BrAMP. Mapping procedures are described in the text. Direction of electrophoresis and chromatography are shown in panel $A$ Panels: (A) Desmin from control myotubes: incorporation of ${ }^{32} \mathrm{PO}_{4}$ into five desmin peptides (A-E) was routinely observed. (B) Desmin from BrcAMP-treated myotubes: a significant increase in ${ }^{32} \mathrm{PO}_{4}$ incorporation into peptides $\mathrm{C}$ and $\mathrm{D}$ is apparent. (C) Desmin from BrAMP-treated myotubes: no change in ${ }^{32} \mathrm{PO}_{4}$ incorporation into any peptide was observed. (D) Desmin phosphorylated in vitro by bovine heart cAMP-dependent protein kinase: peptides corresponding to $A-D$ are apparent. The asterisk denotes a prominent peptide seen in labeled in vitro desmin which was slightly labeled in BrcAMP-treated myotubes (D) but not in control myotubes (A). 
myotubes treated with BrcAMP were qualitatively similar to those of control untreated desmin. The most noticeable difference was a large increase in ${ }^{32} \mathrm{PO}_{4}$ incorporation into the peptides designated $C$ and $D$ (Fig. 3B). Table 2 shows the ${ }^{32} \mathrm{PO}_{4}$ incorporated into each of the five phosphopeptides shown in Fig. $3 \mathrm{~A}$ and $\mathrm{B}$. The relative incorporation (normalized to peptide $A$ ) is also shown (data obtained from two independent experiments). There was an approximate 7- to 10-fold increase in the incorporation of ${ }^{32} \mathrm{PO}_{4}$ into peptides $C$ and $D$, whereas peptides $A, B$, and $E$ remained unchanged. This increase was sufficient to account for a 2.5 -fold increase in ${ }^{32} \mathrm{PO}_{4}$ incorporation into total desmin. Comparison of $\alpha$ - and $\alpha^{\prime}$-desmin from BrcAMP-treated cells revealed little qualitative difference; both $\alpha$ - and $\alpha^{\prime}$-desmin showed increases in ${ }^{32} \mathrm{PO}_{4}$ incorporation into peptides $\mathrm{C}$ and $\mathrm{D}$ (data not shown). Treatment of cells with BrAMP had no effect on the phosphorylation of desmin peptides (Fig. 3C, Table 2), consistent with the lack of increased ${ }^{32} \mathrm{PO}_{4}$ incorporation into BrAMPtreated myotubes.

We have previously reported that desmin peptides $\mathbf{A}$ and $\mathbf{B}$ are phosphorylated at serine residues (20). Partial acid hydrolysis of peptides C and D revealed that they also contain serine as the phosphorylated amino acid (data not shown).

Comparison of the phosphopeptide maps of desmin labeled in vivo with desmin phosphorylated in vitro by bovine heart cAMP-dependent protein kinase revealed several similarities. Peptides A-D were clearly identifiable in both the in vivo and the in vitro labeled desmin (Fig. 3A and D). Peptide $E$, which was present in the in vivo labeled desmin, was not apparent in desmin labeled in vitro. A prominent peptide (Fig. 3D, asterisk) observed in the desmin labeled in vitro was not apparent in the control myotubes la- beled in vivo (Fig. 3A), but was weakly labeled in BrcAMP-treated myotubes (Fig. 3B).

The relative occupancy of the observed desmin peptides under normal growth conditions were determined by labeling 8-day-old myotubes with ${ }^{32} \mathrm{PO}_{4}$ for intervals of 2 to $24 \mathrm{~h}$ in minimal essential medium supplemented with $10 \%$ horse serum and $2 \%$ chicken embryo extract. Total incorporation of ${ }^{32} \mathrm{PO}_{4}$ into desmin was observed to approach a plateau by $24 \mathrm{~h}$ (data not shown). The incorporation into individual peptides at $24 \mathrm{~h}$ and the incorporation relative to total ${ }^{32} \mathrm{PO}_{4}$ in desmin is shown in Table 2 . We concluded that the incorporation of ${ }^{32} \mathrm{PO}_{4}$ into individual peptides relative to the total ${ }^{32} \mathrm{PO}_{4}$ incorporated into desmin represents the relative occupancy of each of the phosphorylation sites on desmin. Peptides $\mathrm{C}$ and $\mathrm{D}$ together represented only approximately $7 \%$ of the total phosphate in desmin (Table 2).

Phosphorylation during myogenesis. Incorporation of radioactive phosphate into both desmin and vimentin was observed during all stages of myogenesis in vitro. In secondary myogenic cultures at $6 \mathrm{~h}$ after being plated, which consist predominantly of unfused replicating myoblasts, vimentin is the major IF protein, whereas des$\mathrm{min}$ is a minor protein species restricted to the few fusing myoblasts or young myotubes (9). Although ${ }^{32} \mathrm{PO}_{4}$ incorporation was greatest in vimentin (Fig. 4A and $\mathrm{B}$ ), a ${ }^{32} \mathrm{PO}_{4}$-labeled species identifiable as $\alpha$-desmin was detectable (Fig. 4A, arrow). By $24 \mathrm{~h}$ after plating phosphorylated desmin was prevalent, with both $\alpha$ - and $\alpha^{\prime}$-desmin identifiable (data not shown). At later stages $(4,7$, or 19 days), desmin represented one of the major cellular phosphoproteins along with vimentin and tropomyosin (see Fig. 1, 2, 4B, and C). The observed increase in phosphorylated desmin presumably parallels the increase in synthesis of desmin and its cytoplasmic accumula-

TABLE 2. Incorporation of label into desmin phosphopeptides

\begin{tabular}{|c|c|c|c|c|c|c|c|c|c|}
\hline \multirow{3}{*}{ Peptide } & \multicolumn{9}{|c|}{${ }^{32} \mathrm{PO}_{4}$ incorporation into 8-day-old myotubes with ${ }^{a}:$} \\
\hline & \multicolumn{2}{|c|}{ No addition } & \multicolumn{2}{|c|}{$\operatorname{BrcAMP}(1 \mathrm{mM}, 1 \mathrm{~h})$} & \multicolumn{2}{|c|}{ BrAMP (1 mM, 1 h) } & \multicolumn{3}{|c|}{ 24-h incubation ${ }^{b}$} \\
\hline & $\mathbf{P}$ & $\mathbf{R}$ & $\mathbf{P}$ & $\mathbf{R}$ & $\mathbf{P}$ & $\mathbf{R}$ & $\mathbf{P}$ & $\mathbf{R}$ & $\mathbf{0}$ \\
\hline $\begin{array}{l}\mathbf{A} \\
\mathbf{B} \\
\mathbf{C} \\
\mathbf{D} \\
\mathbf{E}\end{array}$ & $\begin{array}{r}1,077 \\
174 \\
151 \\
63 \\
285\end{array}$ & $\begin{array}{c}1.0 \\
0.14 \pm 0.02 \\
0.18 \pm 0.04 \\
0.06 \pm 0.01 \\
0.21 \pm 0.05\end{array}$ & $\begin{array}{r}764 \\
128 \\
1,651 \\
336 \\
208\end{array}$ & $\begin{array}{c}1.0 \\
0.15 \pm 0.02 \\
2.1 \pm 0.07 \\
0.40 \pm 0.04 \\
0.24 \pm 0.04\end{array}$ & $\begin{array}{r}651 \\
106 \\
93 \\
32 \\
165\end{array}$ & $\begin{array}{c}1.0 \\
0.15 \pm 0.03 \\
0.15 \pm 0.01 \\
0.04 \pm 0.01 \\
0.22 \pm 0.03\end{array}$ & $\begin{array}{r}923 \\
165 \\
80 \\
12 \\
231\end{array}$ & $\begin{array}{l}1.0 \\
0.18 \\
0.09 \\
0.01 \\
0.25\end{array}$ & $\begin{array}{l}0.65 \\
0.12 \\
0.06 \\
0.01 \\
0.16\end{array}$ \\
\hline Total & 1,750 & $1.6 \pm 0.1$ & 3,087 & $3.9 \pm 0.2$ & 1,047 & $1.6 \pm 0.1$ & 1,411 & 1.5 & 1.0 \\
\hline
\end{tabular}

a Myotubes were labeled for $4 \mathrm{~h}$ with ${ }^{32} \mathrm{PO}_{4}(100 \mu \mathrm{Ci} / \mathrm{ml})$, and BrcAMP or BrAMP was added. P, Total ${ }^{32} \mathrm{PO}_{4}$ label incorporation per peptide (one representative experiment); $R$, incorporation of label into peptides B-E relative to peptide $\mathrm{A}$ (two experiments \pm range).

${ }_{b}$ Myotubes were labeled with ${ }^{32} \mathrm{PO}_{4}(200 \mu \mathrm{Ci} / \mathrm{ml})$ for $24 \mathrm{~h}$ (see the text) to determine the relative occupancy (O) of each peptide ( $O$ equals amount of label in individual peptide divided by amount of label in total desmin). 

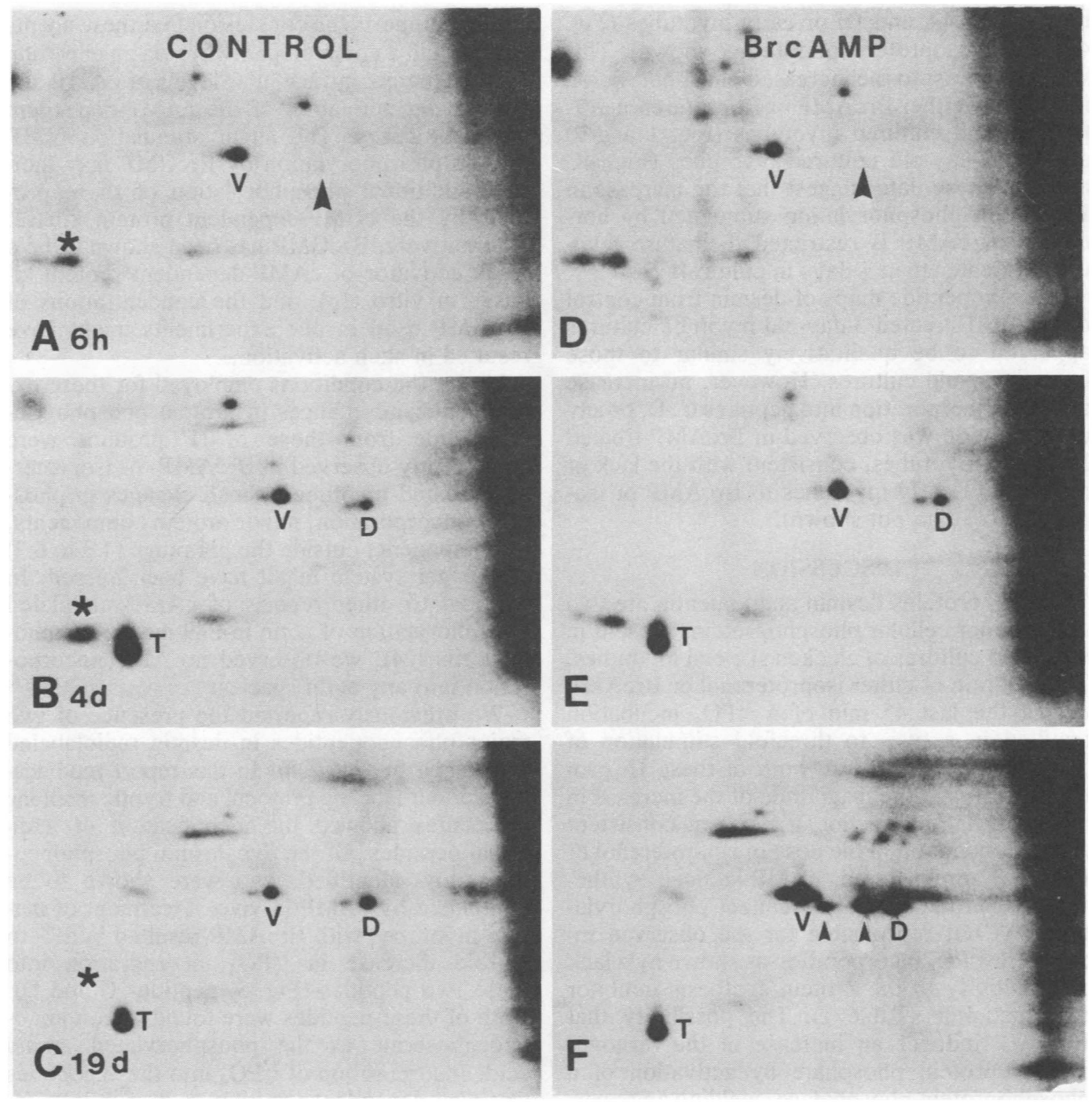

FIG. 4. Phosphorylation during myogenesis. Myogenic cultures were labeled for $4 \mathrm{~h}$ with ${ }^{32} \mathrm{PO}_{4}$. BrcAMP and theophylline were added during the last $45 \mathrm{~min}$ to final concentrations of $1 \mathrm{mM}$ (panels $D$ and $E$ ) or $0.5 \mathrm{mM}$ (panel F). Phosphorylation of desmin (D) and vimentin (V) was apparent in control cultures at all times examined. In 6-h myoblasts (A), desmin (arrow) is a minor component (see text). After 4 (B) and 19 (C) days, desmin represents one of the major cellular phosphate acceptors. No increase in ${ }^{32} \mathrm{PO}_{4}$ incorporation into desmin or vimentin was seen in BrcAMP-treated myoblasts (D) or 4-day-old myotubes (E). Previous figures (1-3) showed significant BrcAMP-induced phosphorylation increases in 7- to 8-day-old myotubes. This increase was also apparent in 19day-old myotubes (panel F). Arrows in D indicate $\alpha-, \alpha^{\prime}-$, and a third desmin variant. T, Tropomyosin; *, a cellular phosphoprotein which is diminished in 19-day-old myotubes. Autoradiograms were exposed for $24 \mathrm{~h}$.

tion during myogenesis (9). Several other phosphoproteins were present in altered amounts during myogenesis. For example, ${ }^{32} \mathrm{P}$-labeled muscle tropomyosin is a very minor component in 6-h cultures, but increases substantially during myogenesis as the intracellular concentration of tropomyosin increases (9). Conversely, phosphorylation of another prominent cellular protein prevalent in early myoblasts was sub- stantially reduced during the course of differentiation (Fig. 4, asterisks). A phosphoprotein with similar pI and electrophoretic mobility was also observed in non-muscle chicken embryo fibroblast cultures and BHK-21 cells (data not shown). This protein was not identified.

No changes in the phosphorylation of desmin and vimentin were apparent in autoradiograms from isoproterenol- or BrcAMP-treated myo- 
blasts (Fig. 4A and D) or early myotubes (Fig. 4B and $E$; isoproterenol data not shown). This was in contrast to the increased phosphorylation induced by either BrcAMP or isoproterenol in 7to 8-day-old cultured myotubes (Fig. 1 and 2) and in 19-day-old cultured myotubes (Fig. 4C and F). These data suggest that the increase in IF protein phosphorylation stimulated by hormones or CAMP is restricted to mature myotubes (greater than 7 days in culture).

Phosphopeptide maps of desmin from control or BrcAMP-treated 3-day-old myotube cultures appeared to be qualitatively similar to those from 8-day-old cultures. However, no increase in ${ }^{32} \mathrm{PO}_{4}$ incorporation into peptides $\mathrm{C}, \mathrm{D}$, or any other peptide was observed in BrcAMP-treated 3-day-old myotubes, consistent with the lack of response of early myotubes to BrcAMP or isoproterenol (data not shown).

\section{DISCUSSION}

The IF proteins desmin and vimentin are two of the major cellular phosphoproteins present in 8-day-old cultures of chicken skeletal myotubes. The addition of either isoproterenol or BrcAMP during the last $45 \mathrm{~min}$ of a ${ }^{32} \mathrm{PO}_{4}$ incubation resulted in a two- to threefold stimulation of ${ }^{32} \mathrm{PO}_{4}$ incorporation into both of these IF proteins. Although the magnitude of the increase in phosphorylation was not large, it was consistent and dependent upon the dose of isoproterenol or BrcAMP administered. cAMP-induced synthesis of IF proteins and subsequent phosphorylation was not repsonsible for the observed increase in ${ }^{32} \mathrm{PO}_{4}$ incorporation as shown by a lack of sensitivity to the protein synthesis inhibitor cycloheximide (Table 1 ). The possibility that BrcAMP induces an increase in the turnover rate of protein phosphate by activation of a phosphoprotein phosphatase, yielding an apparent increase in IF protein phosphorylation, was made unlikely by the lack of increased ${ }^{32} \mathrm{PO}_{4}$ incorporation into desmin and vimentin in myotubes treated for 2 to $48 \mathrm{~h}$ with BrcAMP before being labeled with ${ }^{32} \mathrm{PO}_{4}$. Finally, BrcAMP was found to have no effect on the incorporation of ${ }^{32} \mathrm{PO}_{4}$ into the cellular ATP pool. From these data we concluded that $\beta$-adrenergic hormones such as isoproterenol and cAMP derivatives such as BrcAMP stimulate actual increases in the phosphorylation of the IF proteins desmin and vimentin in 8-day-old myotubes. The lack of response to added BrAMP indicated specificity for cyclic nucleotides. BrcAMP has been shown to be a potent activator of the cAMP-dependent protein kinases (16), suggesting that these enzymes are responsible for the observed increase in phosphorylation. The lack of an additive response when isoproterenol and BrcAMP were added at saturating concentrations to the same culture supports the conclusion that these agents act through a common pathway, via an elevation in the effective intracellular levels of cAMP and subsequent activation of the CAMP-dependent protein kinases. The slight stimulation of IF protein phosphorylation by BrcGMP may indicate additional phosphorylation of these proteins by the cGMP-dependent protein kinase. Alternatively, BrcGMP has been shown to be a weak activator of cAMP-dependent protein kinases in vitro (16), and the concentrations of BrcGMP used in our experiments might have resulted in such activation.

Under the conditions employed for these experiments, no changes in protein phosphorylation aside from those of IF proteins were consistently observed in BrcAMP- or isoproterenol-treated myotubes. Small changes in phosphate incorporation, minor protein components, or components outside the $\mathrm{pH}$ range (4.3 to 6.2) of our gel system might have been missed. In contrast to other reports of cAMP-modulated phosphorylation of actin in S49 mouse lymphoma cells (24), we observed no ${ }^{32} \mathrm{PO}_{4}$ incorporation into any actin species.

We previously reported the presence of two major phosphopeptides in desmin radiolabeled with ${ }^{32} \mathrm{PO}_{4}$ in vivo (20). In this report modifications of our labeling protocol and tryptic mapping procedures allowed the identification of additional peptides. Of the five desmin phosphopeptides now identified, two were shown to be modulated by cAMP in vivo. Treatment of mature myotubes with BrcAMP resulted in a 7- to 10-fold increase in ${ }^{32} \mathrm{PO}_{4}$ incorporation into these two peptides (Fig. 3, peptides C and D). Both of these peptides were found to contain $o$ phosphoserine as the phosphorylated amino acid. Incorporation of ${ }^{32} \mathrm{PO}_{4}$ into these peptides was also dependent upon myotube culture conditions and could be markedly reduced by serum starvation (unpublished data).

Four of the five desmin phosphopeptides observed in vivo, including peptides $C$ and $D$, were also identified in ${ }^{32} \mathrm{P}$-labeled desmin phosphorylated in vitro by cAMP-dependent protein kinase. Although the phosphorylation of sites corresponding to these peptides by another kinase with identical specificity cannot be ruled out, this evidence suggests that most of the desmin phosphopeptides are phosphorylated by the cAMP-dependent protein kinase. The differences noted between the relative labeling of the desmin phosphopeptides in vivo and in vitro presumably reflects factors including site accessibility and occupancy in vivo rather than distinct kinase specificities. Of the in vivo desmin phosphopeptides, only peptide $E$ could not be identified in demsin phosphorylated in vitro. We can draw no conclusions about the kinase re- 
sponsible for phosphorylating peptide $\mathrm{E}$ at this time.

We previously concluded that the most basic species of desmin and vimentin represent the unmodified translation products and that subsequent phosphorylation reactions give rise to the more acidic variants (19). We were thus puzzled by the lack of perceptible changes in the ratio of desmin isoelectric species after BrcAMP-induced increases in phosphorylation. Because the ${ }^{32} \mathrm{PO}_{4}$ labeling period used $(4 \mathrm{~h}$ in most experiments) was significantly shorter than that required for phosphorylated IF proteins to reach a constant specific activity equal to that of the cellular ATP pool, the relative increase in ${ }^{32} \mathrm{PO}_{4}$ incorporation which we report for BrcAMP or isoproterenol was disproportionate to the actual increase in phosphorylation. The two- to threefold increase in total ${ }^{32} \mathrm{PO}_{4}$ in desmin (corresponding to a seven- to tenfold increase in ${ }^{32} \mathrm{PO}_{4}$ in peptides $C$ and $D$ ) cannot be construed as representing a two- to threefold increase in total phosphorylation of desmin. The lack of a detectable difference in the ratio of Coomassie-stained desmin variants after treatment with BrcAMP suggests that the actual increase must be less. Based upon our estimates of the relative occupancy of the desmin phosphorylation sites A-E (corresponding to peptides A-E) under normal growth conditions (Table 2), a twofold increase in actual phosphorylation at sites $C$ and $D$ would result in an increase of less than $10 \%$ in the total phosphate in desmin. Such an increase, when distributed among the desmin isoelectric variants, could result in changes in the ratios of the desmin isoelectric variants which are below the resolution of our techniques.

Phosphorylation of both desmin and vimentin was apparent at all stages of myogenesis examined. However, the sensitivity of phosphorylation to stimulation by BrcAMP or isoproterenol was observed only in mature myotubes (7 to 8 days after culture). The basis for this difference in sensitivity during myogenesis is not yet known. Both cAMP levels and levels of active cAMP-dependent protein kinase have been shown to vary during early myogenesis (28). It is possible that in early myoblast or myotube cultures higher endogenous cAMP levels may result in maximal phosphorylation of cAMP-modulated sites. The addition of exogenous cAMP could not then stimulate ${ }^{32} \mathrm{PO}_{4}$ incorporation into IF proteins over that caused by turnover of previously bound phosphate. It is interesting that the two non-muscle cell types examined responded differently to BrcAMP and isoproterenol. Increases in phosphorylation of vimentin were observed in chicken embryo fibroblast cells treated with BrcAMP or isoproterenol, but no increases were seen in similarly treated
BHK-21 cells, which contain both desmin and vimentin (unpublished data; see also references 3 and 5). This also might reflect differences in endogenous intracellular cAMP levels.

The function of IF phosphorylation has not been conclusively established. No differences in the polymerization properties of BHK cell IF proteins in the phosphorylated or unphosphorylated state have been detected $(26,27)$. Similarly, phosphorylation has no observable effect on the assembly of desmin and vimentin into Triton-KCl-insoluble myotube cytoskeletons (18); the BrcAMP-stimulated increase in myotube IF protein phosphorylation observed in whole cell extracts was also seen in analyses of cytoskeletons treated with Triton X-100 (unpublished data). We find it intriguing, however, that the increase in sensitivity of IF protein phosphorylation during myogenesis corresponded chronologically with the redistribution of cytoplasmic IFs to the myofibril $\mathrm{Z}$ line during late myogenesis which we described previously (9). Although the mechanisms which regulate this reorganization of IFs are, as yet, unknown, this coincidence suggests that phosphorylation of IF proteins by cAMP-dependent protein kinase may be involved. Preliminary immunofluorescence studies indicate that treatment of myotubes with either BrcAMP or isoproterenol can reversibly inhibit this redistribution of IFs to the $Z$ line. We are tempted to speculate that this inhibition is related to the observed increases in phosphorylation of IF proteins stimulated by these agents.

In summary, we have reported that $\beta$-adrenergic agonists such as isoproterenol and cAMP analogs stimulate increases in the phosphorylation of the IF proteins desmin and vimentin in 8day-old myotubes cultured in vitro and have identified specific desmin phosphopeptides whose phosphorylation is increased in BrcAMPtreated 8-day-old myotubes. Although mature (7- to 8-day-old) myotubes showed increases in phosphorylation, myoblasts showed no changes in phosphorylation when exposed to either agonists or cAMP analogs. These data, in conjunction with our previous studies of cAMP-dependent phosphorylation of desmin and vimentin in vitro $(18,19)$, suggest that the IF proteins desmin and vimentin are phosphorylated by the cAMP-dependent protein kinase in vivo and that changes in intracellular cAMP levels during differentiation may modulate IF protein phosphorylation and thereby regulate IF function.

\section{ACKNOWLEDGMENTS}

We thank Clare M. O'Connor for preparing in vitro phosphorylated desmin and the assay for ATP and Ilga Lielausis for assistance in preparing myogenic cell cultures. We also thank Dr. O'Connor, Mary Kennedy, Bruce L. Granger, and 
Chung Wang for helpful discussion during the course of this research and preparation of this manuscript.

This work was supported by Public Health Service grant no. GM 06965 from the National Institutes of Health, grants from the National Science Foundation and Muscular Dystrophy Association of America, and a Biomedical Research Support Grant to the Division of Biology, California Institute of Technology. D.L.G. was also supported by Predoctoral Training grant no. GM 07616 and E.L. is the recipient of a Research Career Development Award, both from the National Institutes of Health.

\section{LITERATURE CITED}

1. Bennett, G. S., S. A. Fellini, Y. Toyama, and H. Holtzer. 1979. Redistribution of intermediate filament subunits during skeletal myogenesis and maturation in vitro. J. Cell Biol. 82:577-584.

2. Browning, E. T., and M. M. Sanders. 1981. Vimentin: a phosphoprotein under hormonal regulation. J. Cell Biol. 90:803-808.

3. Cabral, F., and M. M. Gottesman. 1979. Phosphorylation of the $10 \mathrm{~nm}$ filament protein from Chinese hamster ovary cells. J. Biol. Chem. 254:6203-6206.

4. Dolecki, G., D. Anderson, and L. D. Smith. A quantitative method for the measurement of cellular guanosine triphosphate pool specific activities. Anal. Biochem. 71:37-41.

5. Evans, R. M., and L. M. Fink. 1982. An alteration in the phosphorylation of vimentin-type intermediate filaments is associated with mitosis in cultured mammalian cells. Cell 29:43-52.

6. Fellini, S. A., G. S. Bennett, Y. Toyawa, and H. Holtzer. 1978. Biochemical and immunological heterogeneity of $100 \AA$ filament subunits from different chick cell types. Differentiation 12:59-69.

7. Franke, W. W., E. Schmid, M. Osborn, and K. Weber. 1978. Different intermediate sized filaments distinguished by immunofluorescence microscopy. Proc. Natl. Acad. Sci. U.S.A. 75:5034-5038.

8. Gard, D. L., P. B. Bell, and E. Lazarides. 1979. Coexistence of desmin and fibroblastic intermediate filament subunit in muscle and non-muscle cells: identification and comparative peptide analysis. Proc. Natl. Acad. Sci. U.S.A. 76:3894-3898.

9. Gard, D. L., and E. Lazarides. 1980. The synthesis and distribution of desmin and vimentin during myogenesis in vitro. Cell 19:263-275.

10. Granger, B., and E. Lazarides. 1978. The existence of an insoluble $\mathbf{Z}$ disc scaffold in chicken skeletal muscle. Cell 15:1253-1268.

11. Granger, B., and E. Lazarides. 1979. Desmin and vimentin coexist at the periphery of the myofibril $Z$ disc. Cell 18:1053-1063.

12. Hubbard, B. D., and E. Lazarides. 1979. Copurification of actin and desmin from chicken smooth muscle and their copolymerization in vitro to intermediate filaments. J. Cell Biol. 80:166-182.

13. Krebs, E. G., and J. A. Beavo. 1979. Phosphorylationdephosphorylation of enzymes. Annu. Rev. Biochem.
48:923-959.

14. Lazarides, E. 1980 . Intermediate filaments as mechanical integrators of cellular space. Nature (London) 283:249 256.

15. Michal, G., M. Nelbock, and G. Weiman. 1970. Cyclophosphate III. Spaltung verschiedener Cyclophosphate durch Phosphodiesterase aus Herz und Fettgewebe. Z. Anal. Chem. 252:189.

16. Miller, J. P., K. H. Boswell, K. Muneyama, L. N. Simon, R. K. Robins, and D. A. Shuman. 1973. Synthesis and biochemical studies of various 8-substituted derivatives of guanosine $3^{\prime}, 5^{\prime}$-cyclic phosphate, inosine $3^{\prime}, 5^{\prime}$-cyclic phosphate, and xanthosine $3^{\prime}, 5^{\prime}$-cyclic phosphate. Biochemistry 12:5310-5319.

17. O'Connor, C. M., D. J. Asai, C. N. Fytzanis, and E. Lazarides. 1981. In vitro translation of the intermediate filament proteins desmin and vimentin. Mol. Cell. Biol. 1:303-309.

18. O'Connor, C. M., D. R. Balzer, and E. Lazarides. 1979. Phosphorylation of the subunit proteins of intermediate filaments from chicken muscle and non-muscle cells. Proc. Natl. Acad. Sci. U.S.A. 76:819-823.

19. O'Connor, C. M., D. L. Gard, D. J. Asai, and E. Lazarides. 1981. Phosphorylation of the intermediate filament proteins desmin and vimentin in muscle cells, p. 11571169. In O. M. Rosen and E. G. Krebs (ed.), Protein phosphorylation, vol. 8. Cold Spring Harbor Conferences on Cell Proliferation. Cold Spring Harbor Laboratory, Cold Spring Harbor, N.Y.

20. O'Connor, C. M., D. L. Gard, and E. Lazarides. 1981. Phosphorylation of intermediate filament proteins by cAMP-dependent protein kinases. Cell 23:135-143.

21. O'Farrell, P. H. 1975. High resolution two-dimensional electrophoresis of proteins. J. Biol. Chem. 250:4007-4021.

22. Simantov, R., T. Shlonit, and L. Sachs. 1980. Desensitization of enucleated cells to hormones and the role of cytoskeleton in control of normal hormone response. Proc. Natl. Acad. Sci. U.S.A. 77:4798-4802.

23. Small, J. V., and A. Sobieszek. 1977. Studies on the function and composition of the $10 \mathrm{~nm}(100-\AA)$ filaments of vertebrate smooth muscle. J. Cell Sci. 23:243-268.

24. Steinberg, R. A. 1980 . Actin nascent chains are substrates for cyclic AMP-dependent phosphorylation in vivo. Proc. Natl. Acad. Sci. U.S.A. 77:910-914.

25. Steinberg, R. A., and P. Cofino. 1979. Two-dimensional gel analysis of cyclic AMP effects in cultured S49 mouse lymphoma cells: protein modifications, inductions and repressions. Cell 18:719-733.

26. Steinert, P. M., W. W. Idler, F. Cabral, M. M. Gottesman, and R. D. Goldman. 1981. In vitro assembly of homopolymer and copolymer filaments from intermediate filament subunits of muscle and fibroblastic cells. Proc. Natl. Acad. Sci. U.S.A. 78:3692-3696.

27. Steinert, P. M., W. W. Idler, and M. L. Wantz. 1982. The o-phosphoserine content of intermediate filament subunits. Biochemistry 21:177-183.

28. Zalin, R. J., and W. Montague. 1974. Changes in adenylate cyclase, cyclic AMP, and protein kinase levels in chick myoblasts, and their relation to differentiation. Cell 2:103-108. 